\title{
Analisa Quality of Service Menggunakan Aplikasi Gnump3d sebagai Server Media Streaming
}

\section{Quality Of Service Analysis Using the Gnump3d Application as a Streaming Media Server}

\author{
Raisul Azhar ${ }^{*}$, Heroe Santoso ${ }^{2}$, Faisal $^{3}$ \\ ${ }_{1,2,3}$ Universitas Bumigora \\ raisulazhar@universitasbumigora.ac.id ${ }^{1 *}$, Heroe.Santoso@universitasbumigora.ac.id ${ }^{2}$, \\ 1510520172@universitasbumigora.ac.id ${ }^{3}$
}

\begin{abstract}
Abstrak - Streaming merupakan istilah sebuah file video maupun audio yang dapat dimainkan tanpa terlebih dahulu dilakukan pengunduhan terhadap file yang dijalankan. Banyak sekali aplikasi yang digunakan untuk menjalankan audio dan video streaming contohnya seperti Gnump3d, Spotify, Joox, Deezer dan lain sebagainya. Semua aplikasi tersebut tidak menjamin kualitas layanan atau QoS yang baik jika dijalankan pada jaringan internet yang melewati banyak perangkat jaringan komputer. Permasalahan QoS terutama pada media Audio Streaming tidak akan banyak terjadi pada Server phisik akan tetapi akan terjadi jika aplikasi tersebut dipasangkan pada Virtual Private Server (VPS). Tujuan dari penelitian ini adalah mengetahui tingkat QoS yang dihasilkan oleh Sebuah Aplikasi Gnump3d yang terpasang pada VPS dengan mengamati parameter Delay,Jiiter,Packet Loss dan Throughput. Metodologi penelitian menggunakan sebagaian tahapan metodologi Network Development Life Cycle yaitu analis, desain dan simulasi prototype. Kesimpulan penelitian ini menghasilkan QoS audio streaming yang berkualitas sangat bagus berdasarkan standard TIPHON pada parameter delay, packet loss dan Througput, jika diuji coba dengan bentuk variasi bandwidth $128 \mathrm{kbps}, 256 \mathrm{kbps}$, $512 \mathrm{kbps}$ dan delay 30sec, 60sec, 90sec diperoleh nilai parameter delay dengan rata-rata $44,94 \mathrm{~ms}<150 \mathrm{~ms}$, Packet Loss dengan rata-rata prosentase $0.33 \%<5 \%$ dan Througput 269kbit/s $>100$. Sedangkan QoS yang buruk dihasilkan oleh paramter Jitter Sebesar $11.675 \mathrm{~ms}$ yang melebihi dari range $125 \mathrm{~ms}-255 \mathrm{~ms}$ yang tetapkan TIPHON.
\end{abstract}

Kata Kunci: Audio, Streaming, Server, QoS

\begin{abstract}
Streaming is the term for a video or audio file that can be played without first downloading the file that is running. There are so many applications that are used to run audio and video streaming, such as Gnump3d, Spotify, Joox, Deezer and so on. All of these applications do not guarantee quality of service or good QoS if run on the internet network that passes through many computer network devices. QoS problems, especially on Audio Streaming media, will not occur much on physical servers but will occur if the application is installed on a Virtual Private Server (VPS). The purpose of this research is to determine the level of QoS generated by a Gnump3d application installed on a VPS by observing parameters Delay, Jiiter, Packet, Loss and Throughput. The research methodology uses several stages of the Network Development Life Cycle methodology, namely analysis, design and prototype simulation. The conclusion of this study resulted in a very good quality QoS audio streaming based on the TIPHON standard on the parameters of delay, packet loss and throughput, if tested in the form of bandwidth variations of $128 \mathrm{kbps}$, $256 \mathrm{kbps}, 512 \mathrm{kbps}$ and delay $30 \mathrm{sec}, 60 \mathrm{sec}$, $90 \mathrm{sec}$, the delay parameter values obtained on average $44.94 \mathrm{~ms}$ $<150 \mathrm{~ms}$, Packet Loss with an average percentage of $0.33 \%<5 \%$ and Througput $269 \mathrm{kbit} / \mathrm{s}>100$. Meanwhile, bad QoS is generated by the Jitter parameter of $11,675 \mathrm{~ms}$ which exceeds the $125 \mathrm{~ms}-255 \mathrm{~ms}$ range that sets TIPHON
\end{abstract}

Keywords: Audio, Streaming, Server, QoS

Jurnal Bumigora Information Technology (BITe)

Vol.3, No.1, Juni 2021, pp. 45-55

ISSN: $2685-4066$

DOI: $10.30812 /$ bite.v3i1 
1. Pendahuluan

Teknologi informasi mengalami perkembangan dalam berbagai faktor dan terus mengalami kemajuan. Dari berbagai kemajuan yang dibuat oleh manusia sampai hari ini yang paling signifikan adalah perkembangan internet. Jaringan internet menjadi salah satu hal yang paling dibutuhkan pada era teknologi informasi seperti saat ini. Internet menjadi kebutuhan primer manusia saat ini karena digunakan 24 jam untuk membantu tugas-tugas manusia disamping digunakan untuk media hiburan, komunikasi dan lain sebagainya. Internet adalah sekumpulan komputer yang saling terhubung dalam suatu jaringan di seluruh dunia tanpa dibatasi oleh jumlah unit yang saling mengakses satu sama lain. Dengan menggunakan internet tersebut, satu komputer dapat berinteraksi secara langsung dengan komputer lain yang ada di berbagai belahan dunia. Internet saat ini sudah hadir di berbagai lingkungan seperti kantor, perusahaan, sekolah, maupun instansi lain, yang menjadi kebutuhkan primer manusia untuk mendukung proses komunikasi baik dilakukan secara audio maupun video streaming [1]

Pemanfaatan Audio Stereaming pada jaringan internet membutuhkan kualitas layanan atau Quality Of Service (QoS) yang baik. Streaming merupakan istilah sebuah file video maupun audio yang dapat dimainkan tanpa terlebih dahulu dilakukan pengunduhan terhadap file yang dijalankan. Streaming juga dapat diartikan sebagai teknik yang digunakan untuk melakukan transfer data sehingga dapat diproses secara tetap dan terus menerus. Streaming merupakan sebuah metode untuk membuat audio, video, dan multimedia yang lain yang tersedia untuk realtime pada tipe jaringan yang berbeda [4]. Audio streaming memainkan berkas suara lewat jaringan sebelum berkas sepenuhnya selesai diunduh. Makin banyaknya orang yang menggunakan audio streaming menimbulkan masalah pada penerapan sistem audio streaming terutama pada sistem konvensional yang terpusat. Dengan sistem terpusat tersebut maka sumberdaya yang dibutuhkan pelayan (server) pusat harus makin besar mengikuti perkembangan pengguna.

Masalah terbesar yang dihadapi dari teknologi audio streaming adalah keterbatasan bandwidth, sedangkan proses komunikasi yang menggunakan digital audio ini menghabiskan resource yang cukup besar. Semakin besar bandwidth yang tersedia, semakin bagus kualitas audio yang ditampilkan. Aplikasi streaming media yang membutuhkan bitrate cukup tinggi menyebabkan beban jaringan bertambah sehingga menyebabkan service yang diberikan tidak dapat berjalan dengan baik.

Penelitian yang dilakukan Gian Geovani[2], Pada penelitian audio streaming yang dilakukan menerapkan pada jaringan komputer berbasis peer to peer dengan metode block scheduling, hal tersebut menyebabkan tidak ada pelayan (server) terpusat yang terbebani, melainkan beban didistribusikan pada pengguna itu sendiri. Penelitian Audio streaming Peer to Peer metode block scheduling diiImplementasikan menggunakan protokol TCP dengan memanfaatkan API Socket. Dari hasil penelitiannya beban pelayanan audio streaming terbagi hampir sama rata dengan hanya memperhatikan parameter QoS delay dan througput.

Penelian yanga dilakukan Hasanul Fahmi [3], melakukan analisis QoS kualitas kerja streaming yang baik yang ditujukan pada radio streaming simfoni FM, yang dapat terlihat dari pengukuran delay, packet lost, jitter dan juga throughput. Objek penelitian ini adalah aplikasi streaming radio Simfoni FM. Pada penelitian ini menggunakan metode Model Monitoring QoS yang terdiri dari komponen monitoring application, QoS monitoring, monitor, dan monitored objects. Hasil penelitian yang dilakukan diperoleh dengan memperhatikan beberapa parameter seperti bitrate, delay dan packet loss. Sedangkan kualitas terbaik didapat pada setting bitrate 320 kbps dengan jumlah kanal minimal. Delay dan packet lost yang paling kecil didapat pada nilai bitrate $320 \mathrm{kbps}$.

Penelitian Sutarti [1] Pada penelitian ini dilakukan analisis Quality of Service (QoS) pada layanan jaringan komunikasi VoIP (Voice over Internet Protocol) menggunakan aplikasi softphone X-Lite sebagai software untuk melakukan panggilan dan wireshark sebagai Network analyzer untuk mengukur parameter QoS pada VoIP seperti parameter delay, jitter dan Packet loss. Metode yang digunakan adalah dengan membangun topologi jaringan ujicoba, melakukan 
instalasi, konfigurasi dan melakukan monitoring QoS dengan aplikasi wireshark. Hasil penelitian dapat disimpulkan bahwa kualitas QoS terbaik pada VoIP dilakukan ketika kondisi kondisi jaringan tidak banyak diperguanakan oleh user. Hal tersebut terlihat dari rata-rata delay terbesar $0.02 \mathrm{~ms}$ dan terkecil $0,01 \mathrm{~ms}$, jitter terbesar $11,9 \mathrm{~ms}$ dan terkecil $0,32 \mathrm{~ms}$ ) sedangkan untuk packet loss terbesar $1,71 \%$. dan terkecil $0,00 \%$.

Berdasarkan ketiga peneliti tersebut telah banyak dilakukan penelitian sejenis tentang QoS pada Audio Stereaming dengan melakukan pengamatan terhadap kinerja QoS dalam parameter delay, packet loss, jitter dan throughput, dengan metode dan objek penelitian yang dilakukan berbeda. Penelitian yang dilakukan saat ini terdapat perbedaan dari ketiga peneliti tersebut berdasarkan penempatan aplikasi yang digunakan dan object penelitian yang berbeda. Ketiga peneliti tersebut lebih menekankan penelitian audio streaming yang menempatkan aplikasi tersebut dalam bentuk server phisik sehingga mempengaruhi kualitas QoS audio streaming yang dihasilkan dari sisi penngguna serta sangat dipengaruhi oleh spesifikasi hardware yang dipergunakan, media transmisi, topologi jaringan dan model jaringan yang digunakan.

Penelitian ini diambil dari salah satu aplikasi audio streaming yang banyak beredar saat ini yaitu yaitu Aplikasi Gnump3d berbasis Sistem Operasi Linux yang diterapkan pada perangkat Server Virtual atau Virtual Private Server (VPS) yang banyak dilakukan oleh pengembang multimedia terutama audio maupun video steraming di internet. Aplikasi ini dipilih dari banyak sekali aplikasi yang tersedia menjalankan fungsi audio streaming seperti Spotify, Joox, Deezer dan lain sebagainya. Banyaknya aplikasi tersebut tidak menjamin kualitas layanan (QoS) yang dihasilkan termasuk aplikasi Gnump3d yang baik jika dijalankan pada jaringan internet yang didalamnya melewati banyak perangkat jaringan yang berbeda. Permasalahan QoS pada media Audio Streaming tidak akan banyak terlihat pada Server phisik akan tetapi akan lebih banyak terlihat jika aplikasi audio streaming tersebut dipasang pada sebuah virtual server seperti Virtual Private Server (VPS). Permasalahan ini terjadi disebabkan pada VPS terdapat banyak aplikasi atau resource-rescource lain yang dijalankan oleh sebuah server virtual sehingga mempengaruhi aplikasi yang lain termasuk aplikasi audio streaming. Pengaruh aplikasi audio streaming yang terjadi jika ditempatkan pada VPS seperti kualitas layanan yang buruk seperti terdapat kualitas suara gemerisik, berdengung, melengking, audio yag terputus, kualitas suara yang tidak sesuai dengan suara aslinya dan kecepatan suara yang dihasilkan tidak seimbang. Tujuan dari penelitian ini adalah ingin mengetahui seberapa besar kualitas layanan (QoS) yang dihasilkan pada aplikasi Gnump3d berbasis sistem operasi linux jika aplikasi ini terpasang pada server VPS, sehingga menjadi rekomendasi kepada pengembang konten-konten multimedia terutama dalam menggunakan aplikasi audio streaming di dalam sistem yang dibangunnya.

\section{Metode Penelitian}

Metodologi penelitian yang digunakan dalam penelitian ini adalah metodologi Network Development Life Cycle (NDLC) [4]. NDLC terdiri dari enam tahapan, yaitu analysis, design, simulation prototyping, implementation, monitoring dan management. Model NDLC ini dapat ditunjukan pada Gambar 1

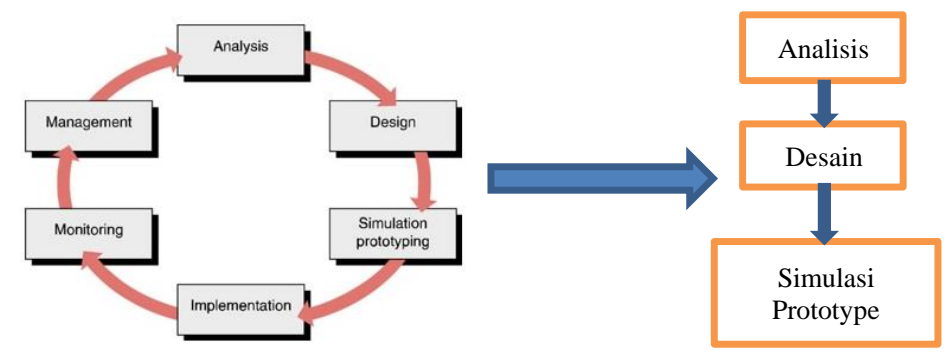

Gambar 1 Model metodologi NDLC [5]. 
Dari ke-enam metodologi yang ada pada NDLC tersebut peneliti hanya mempergunakan tiga tahapan dari enam tahapan metodologi yakni analysis, design dan Simulasi Prototyping. Hasil dari penelitian yang dihasilkan adalah dalam bentuk hasil simulasi yang dibangun berdasarkan topologi jaringan prototype dengan melibatkan perangkat keras dan perangat lunak yang diperlukan untuk mengetahui kualitas QoS audio streaming yang dihasilkan.

\subsection{Analisa Pengumpulan Data}

Pada tahap ini peneliti melakukan Analisa dan pengumpulan data dengan cara studi literature yang diambil dari berbagai sumber seperti jurnal ilmiah, buku ataupun internet untuk mendapatkan informasi terkait penelitian yang dikerjakan terutama difokuskan terkait dengan hasil-hasil penelitian sejenis terkait dengan pengujian Kualitas Layanan atau QoS pada Media streaming. Tahap ini terdiri dari dua bagian yaitu pengumpulan data dan analisa data[6]. Pada Bagian Pengumpulan data yang dilakukan diperoleh adalah banyak sekali aplikasi atau tools yang digunakan untuk menjalankan audio steraming dan ditemukan beberapa hasil pengujian kualitas layanan yang berbeda-beda tergantung metode dan teknik yang digunakan. Dalam menguji QoS pada media audio dan video streaming menggunaan standard Tiphon Menurut Kurnia [7]. QoS merupakan salah satu parameter yang mengacu pada penilaian dari pelayanan trafik jaringan yang diterima oleh server maupun client. Adapun ketentuan parameter $Q o S$ berdasarkan Standard TIPHON yang dipergunakan untuk membandingkan hasil QoS yang dihasilkan berdasarkan pengamatan paramater delay, jitter, packet loss dan throuhput.

\subsubsection{Delay}

Durasi yang dibutuhkan data untuk melintasi dari awal menuju tujuan akhir disebut Delay. Delay berpengaruh pada jarak, saluran fisik, dan penumpukan data sehingga membutuhkan waktu yang Panjang[8]. Delay adalah waktu yang dibutuhkan data untuk menempuh jarak dari asal ketujuan. Delay dapat dipengaruhi oleh jarak, media fisik, kongesti atau juga waktu proses yang lama. Menurut[1]. Delay (Latency) merupakan waktu yang dibutuhkan data untuk menempuh jarak dari asal ke tujuan. Delay dapat dipengaruhi oleh jarak, media fisik, congesti atau juga waktu proses yang lama. Kategori Delay dapat dilihat pada Tabel 1.

Tabel 1 Kategori delay menurut THIPON

\begin{tabular}{ccc}
\hline Kategori Delay & Besar delay $(\mathbf{m s})$ & Indeks \\
\hline Sangat Bagus & $<150$ & 4 \\
Bagus & $150 \mathrm{~ms} \mathrm{~s} / \mathrm{d} 300 \mathrm{~ms}$ & 3 \\
Sedang & $300 \mathrm{~ms} \mathrm{~s} / \mathrm{d} \mathrm{450} \mathrm{ms}$ & 2 \\
Jelek & $>450 \mathrm{~ms}$ & 1 \\
\hline
\end{tabular}

\subsubsection{Jitter}

Jitter merupakan variasi kedatangan paket data. Hal tersebut diakibatkan oleh variasi panjang antrian, waktu pengolahan data, dan waktu penghimpunan ulang paket di akhir perjalanan Jitter [4]. Menurut [9]. Jitter diakibatkan oleh variasi-variasi dalam panjang antrian, dalam waktu pengolahan data, dan juga dalam waktu penghimpunan ulang paket-paket diakhir perjalanan jitter. Kategori Jitter dapat di tunjukan pada Tabel 2.

Tabel 2 Kategori Jitter menurut THIPON.

\begin{tabular}{ccc}
\hline Kategori Jitter & Jitter $(\mathbf{m s})$ & Indeks \\
\hline Sangat Bagus & $0 \mathrm{~ms}$ & 4 \\
Bagus & $0 \mathrm{~ms} \mathrm{~s} / \mathrm{d} 75 \mathrm{~ms}$ & 3 \\
Sedang & $75 \mathrm{~ms} \mathrm{~s} / \mathrm{d} 125 \mathrm{~ms}$ & 2 \\
Jelek & $125 \mathrm{~ms} \mathrm{~s} / \mathrm{d} 255 \mathrm{~ms}$ & 1 \\
\hline
\end{tabular}

\subsubsection{Packet Loss}

Packet Loss merupakan suatu parameter yang menggambarkan suatu kondisi yang menunjukkan jumlah total paket yang hilang dapat terjadi karena collision dan congestion pada jaringan [9]. Packet loss merupakan keadaan yang menginformasikan besaran bagian yang 
tertinggal. Bagian tersebut dapat terjadi karena benturan antar data dan antrian data pada jaringan komputer. Benturan ini berdampak pada seluruh aplikasi, Hal ini karena munculnya proses transmisi ulang yang akan memangkas tingkat efisiensi jaringan komputer secara global. Meskipun jumlah layanan data tersedia dengan layak untuk aplikasi-aplikasi tersebut menurut [8]. Menururt [9]. Packet Loss merupakan suatu parameter yang menggambarkan suatu kondisi yang menunjukkan jumlah total paket yang hilang dapat terjadi karena collision dan congestion pada jaringan. Kategori Packet Loss dapat di tunjukan pada Tabel 3.

Tabel 2 Kategori Packet Loss menurut THIPON.

\begin{tabular}{ccc}
\hline Kategori Packet Loss & Packet Losst (\%) & Indeks \\
\hline Sangat Bagus & 0 & 4 \\
Bagus & 5 & 3 \\
Sedang & 13 & 2 \\
Jelek & 25 & 1 \\
\hline
\end{tabular}

\subsubsection{Throughput}

Throughput yaitu kecepatan (rate) transfer data efektif, yang diukur dalam bps (bit per second). Throughput adalah jumlah total kedatangan paket yang sukses yang diamati pada tujuan selama interval waktu tertentu dibagi oleh durasi interval waktu tersebut [9]. Menurut [8]. Throughput melambangkan ukuran yang aktual dari suatu jaringan komputer dalam proses pengiriman data. Throughput dan bandwidth tidak dapat dipisahkan. Throughput bisa disebut dengan bandwidth dalam kondisi yang sebenarnya namun bandwidth cenderung statis sementara Throughput bersifat dinamis, tergantung pada lalu lintas data yang sedang terjadi. Kategori Throughput dapat di tunjukan pada Tabel 4.

Tabel 3 Kategori Thoughput menurut THIPON

\begin{tabular}{ccc}
\hline Kategori Throughput & Throughput (bps) & Indeks \\
\hline Sangat Bagus & 100 & 4 \\
Bagus & 75 & 3 \\
Sedang & 50 & 2 \\
Jelek & $<25$ & 1 \\
\hline
\end{tabular}

\subsection{Desain}

Pada tahap ini terdiri dari 2 bagian yaitu adalah rancangan jaringan pengujian dan rancangan kebutuhan perangkat keras dan perangkat lunak[8]. Rancangan Jaringan pengujian yang digunakan untuk menguji QoS Audio Steaming dilakukan secara pengujian skala laboratorium dengan membangun topologi jaringan dalam bentuk prototype seperti yang terdapat pada Gambar 2 .

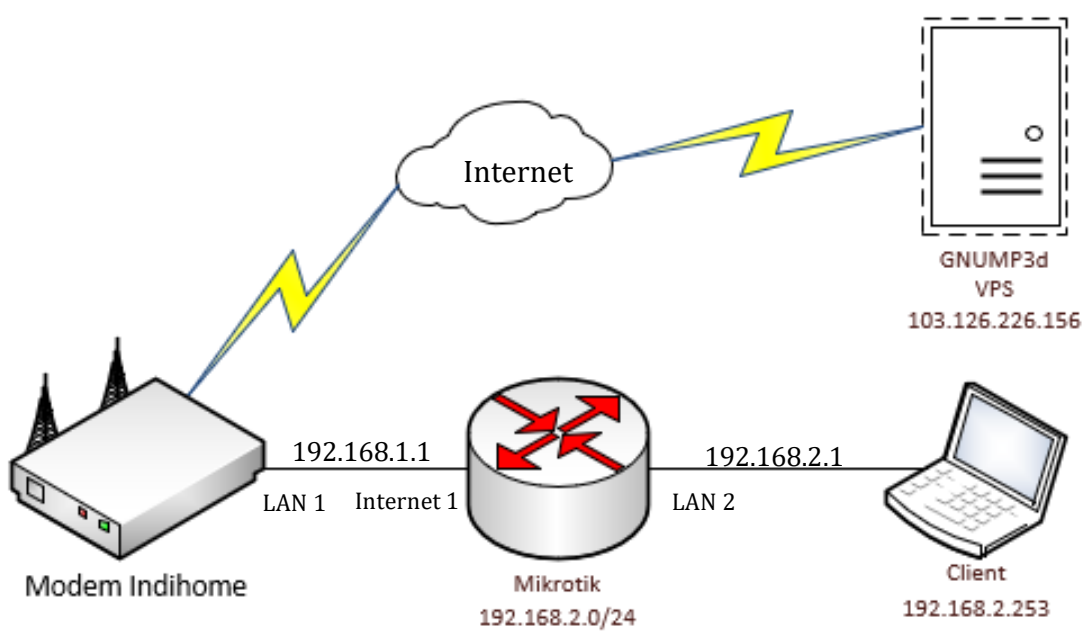

Gambar 2 Rancangan topologi jaringan pengujian 
Prototype ini melibatkan perangkat jaringan 1 Unit Router Mikrotik, Modem Indihome yang terkoneksi langsung dengan Internet, Sebuah Komputer yang berfungsi sebagai Client dan Aplikasi Gnump yang tersangan pada VPS. Pada VPS dilakukan penginstalan ubuntu yang dijadikan sistem operasi server lalu instalasi GNUMP3d yang digunakan sebagai server media streaming kemudian modem indihome digunakan sebagai jaringan untuk uji coba QoS, mikrotik berfungsi sebagai penyalur internet sekaligus limitasi bandwidth pada client untuk pengujian, pada sisi client berfungsi sebagai alat pengujian limitasi bandwidth.

Rancangan Kebutuhan perangkat keras yang digunakan pada pemenelitian ini terdiri dari komputer yang berfungsi sebagai client dan digunakan juga untuk melakukan remote access ke VPS melalui aplikasi PuTTy, spesifikasi dari komputer klient yang digunakan pada penelitian ini seperti pada Tabel 5 .

Tabel 5. Spesifikasi komputer client

\begin{tabular}{cc}
\hline Komponen & Spesifikasi \\
\hline Komputer & Asus \\
CPU & AMD-A9-9420 Radeon R5, 5 \\
& Compute CORES 2C+3G (2 CPUs), \\
& $\sim 3.0 \mathrm{GHz}$ \\
RAM & $4 \mathrm{~GB}$ \\
Hardisk & $1 \mathrm{~TB}$ \\
\hline
\end{tabular}

VPS yang digunakan pada penelitian ini adalah Sistem operasi berbasis Linux Ubuntu 18.04 berfungsi sebagai Server VPS atau sumber daya tempat Instalasi GNUMP3d. Dengan spesifikasi dari VPS dapat pada Tabel 6.

Tabel 6 Tabel spesifikasi VPS

\begin{tabular}{cc}
\hline Komponen & Spesifikasi \\
\hline CPU & 1 CPU Core \\
Memory & $1 \mathrm{~GB}$ \\
RAM & $1 \mathrm{~GB}$ \\
SSD & $20 \mathrm{~GB}$ \\
\hline
\end{tabular}

Selain kebutuhan perangkat pada penelitian ini terdapat pula kebutuhan perangkat lunak yang digunakan adalah sebagai berikut:

a. GNUMP Audio streaming

b. Sistem Operasi Linux Ubuntu 18.04 sebagai VPS

c. Aplikasi Wireshark untuk analis paket data

d. Aplikasi Remote Access dengan menggunakan Putty

e. Aplikasi VLC Client

\subsection{Simulation Prototiping}

Pada tahap ini terdiri dari 4 bagian yaitu adalah instalasi dan konfigurasi pada VPS, konfigurasi pada router, instalasi dan konfigurasi pada Client dan membangun scenario simulasi untuk memperoleh hasil pengamatan berdasarkan standard TIPHON dengan rincian tahapan pengujian sebagai berikut:

a. Instalasi dan Konfigurasi VPS, Pada tahapan ini VPS dilakukan penginstalan ubuntu yang dijadikan sistem operasi server lalu instalasi GNUMP3d yang digunakan sebagai server media streaming [10].

b. Konfigurasi Perangkat Router, Konfigurasi pada mikrotik meliputi pengaturan ip address pada interface. Tahap berikutnya mengatur pembatasan bandwidth menggunakan simple queue untuk limitasi bandwidth pada ip client [7].

c. Konfigurasi Client, Pada sisi client dilakukan instalasi tools wireshark untuk menangkap data pada lalu lintas jaringan dan VLC yang digunakan untuk melakukan pengujian media streaming [11]. 
d. Skenario Pengujian Prototype, dilakukan pada VLC dengan bandwidth yang sudah dilimitasi dengan variasi bandwidth, 128 kbps, 256 kbps, dan 512 kbps yaitu sebagai berikut:

1. Pengujian pada $V L C$ dengan bandwidth 128 kbps dalam waktu $30 \mathrm{sec}, 60 \mathrm{sec}$ dan 90 sec

2. Pengujian pada $V L C$ dengan bandwidth 256 kbps dalam waktu $30 \mathrm{sec}, 60 \mathrm{sec}$ dan 90 sec.

3. Pengujian pada $V L C$ dengan bandwidth 512 kbps dalam waktu $30 \mathrm{sec} 60 \mathrm{sec}$ dan 90 dsec.

\section{Hasil dan Pembahasan}

Berdasarkan metodologi yang diuraikan diatas yang dipergunakan dalam penelitian ini dengan 3 parameter QoS yang telah ditentukan sebelumya yaitu parameter delay, jitter dan packet loss. Hasil analisa dari parameter Delay audio streamig pada $V L C$ berdasarkan hasil capture paket yang dapat ditangkap oleh aplikasi wireshark dengan aturan bandwidth $128 \mathrm{kbps}$ dengan durasi waktu $30 \mathrm{sec}$ seperti yang di tunjukan pada Gambar 3.

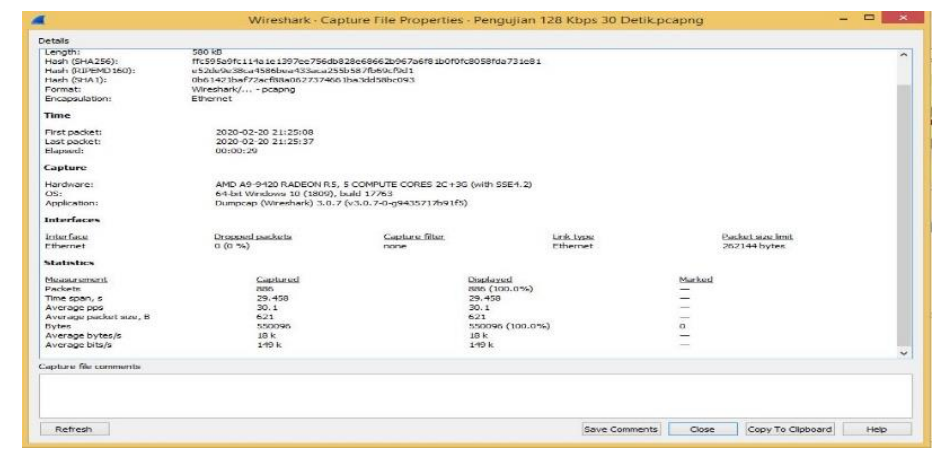

Gambar 3 Hasil capture parameter delay

Pada gambar 3, total paket yang diterima adalah sebanyak 886 paket data dan durasi streaming adalah $29,458 \mathrm{~ms}$ sehingga rata-rata Delay perpaket diperoleh $30,1 \mathrm{~ms}$. Jika dihitung menggunakan rumus secara manual maka diperoleh:

$$
\begin{aligned}
\text { Delay } & =\frac{\text { Total Packet }}{\text { Durasi Streaming }} \\
& =886 / 29,458 \\
& =30,1 \mathrm{~ms}
\end{aligned}
$$

Hasil pengujian lengkap untuk parameter delay dapat terlihat pada tabel 4 dengan delay yang

\begin{tabular}{|c|c|c|c|c|c|c|c|c|c|}
\hline \multicolumn{10}{|c|}{ Hasil Pengujian Parameter Delay } \\
\hline \multirow[b]{2}{*}{ Pengujian } & \multicolumn{3}{|c|}{$30 \mathrm{sec}$} & \multicolumn{3}{|c|}{$60 \mathrm{sec}$} & \multicolumn{3}{|c|}{$90 \mathrm{sec}$} \\
\hline & 128 & 256 & 512 & 128 & 256 & 512 & 128 & 256 & 512 \\
\hline & Kbps & Kbps & Kbps & Kbps & Kbps & Kbps & Kbps & Kbps & Kbps \\
\hline P.1 & 30,1 & 51,1 & 78,2 & 28,5 & 49,7 & 49,8 & 28,6 & 38,5 & 49,2 \\
\hline P. 2 & 29,6 & 52,2 & 82,8 & 28,5 & 50,1 & 46,3 & 28,2 & 39,5 & 47,3 \\
\hline P. 3 & 29,1 & 49,5 & 77,8 & 28,5 & 49,7 & 66,2 & 28,0 & 38,7 & 31,9 \\
\hline P. 4 & 29,7 & 50,6 & 77,1 & 28,4 & 50,3 & 66,2 & 29,8 & 38,5 & 32,3 \\
\hline P.5 & 29,5 & 50,4 & 77,0 & 30,2 & 50,7 & 65,4 & 28,2 & 39,6 & 33,2 \\
\hline
\end{tabular}
bervariasi seperti Tabel 7 .

Tabel 7 Hasil pengujian parameter delay

https://journal.universitasbumigora.ac.id/index.php/bite ISSN: 2685-4066 
Jurnal Bumigora Information Technology (BITe)

\begin{tabular}{clllllllll}
\hline P.6 & 29,3 & 50,3 & 77,1 & 30,9 & 50,6 & 66,5 & 28,2 & 38,6 & 32,4 \\
P.7 & 29,5 & 50,2 & 77,2 & 30,6 & 50,1 & 65,7 & 29,2 & 38,8 & 45,2 \\
Rata-rata & 29,5 & 50,6 & 78,1 & 29,3 & 50,1 & 60,8 & 28,6 & 38,8 & 38,7 \\
& $\mathrm{~ms}$ & $\mathrm{~ms}$ & $\mathrm{~ms}$ & $\mathrm{Ms}$ & $\mathrm{Ms}$ & $\mathrm{Ms}$ & $\mathrm{ms}$ & $\mathrm{Ms}$ & $\mathrm{Ms}$ \\
\hline
\end{tabular}

Dari Tabel 7 diperoleh hasil bahwa kondisi delay cenderung memperoleh hasil yang tidak stabil akan tetapi kesetabilan diperoleh di angka $40 \mathrm{~ms}$ dan pada pengujian selama 30 detik ratarata delay paling besar didapat pada bandwidth $512 \mathrm{kbps}$ yaitu $78,1 \mathrm{~ms}$, pada pengujian selama 60 detik rata-rata delay paling besar didapat pada bandwidth $512 \mathrm{kbps}$ yaitu 60,8 ms. Dan pada pengujian selama 90 detik rata-rata delay paling besar didapat pada bandwidth $256 \mathrm{kbps}$ yaitu 38,8 ms. Kemudian jika dilakukan perbandingan delay pada pengujian selama 30 detik dan 60 detik, nilai delay yang lebih baik didapatkan pada pengujian selama 60 detik. Meskipun begitu, delay yang didapat dari hasil pengujian masih terhitung sangat bagus karena delay dengan kategori sangat bagus yaitu lebih kecil dari $150(<150)$ sesuai dengan standar/kategori nilai TIPHON. Delay adalah waktu yang dibutuhkan data untuk menempuh jarak dari asal ketujuan. Delay dapat dipengaruhi oleh jarak, media fisik, kongesti atau juga waktu proses yang lama. Jka dibandingkan Dengan Standar Nilai TIPHON yang menjadi dasar menentukan nilai dari QoS audio streaming, maka nilai yang diperoleh termasuk katagori Sangat Bagus atau $<150$ dengan indeks 4.

Disamping dilakukan pengujian parameter delay juga dilakukan pengujian pada parameter packet loss, dimana pengujian Packet Loss merupakan suatu parameter yang menggambarkan suatu kondisi yang menunjukkan jumlah total paket yang hilang dapat terjadi karena collision dan congestion pada jaringan, seperti yang tercapture oleh aplikasi wireshark ketika pada posisi pengujian pada badwidh $128 \mathrm{Kbps}$ dengan durasi 30 detik.

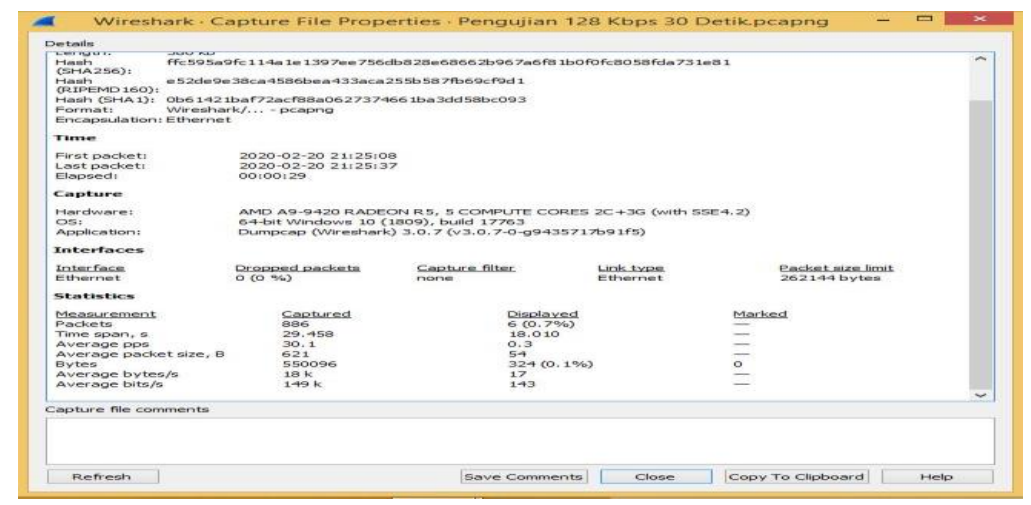

Gambar 4 Hasil capture packet loss

Pada Gambar 4 terlihat Packet loss dari pengujian ini adalah 0,7\%, Jika dihitung menggunakan rumus secara manual seperti pada Persamaan 2.

$$
\begin{aligned}
\text { Packet loss } & =\frac{\text { Paket data yang dikirim-paket data yang diterima }}{\text { Paket data yang dikirim }} \times 100 \% \\
& =886-880 / 886 \times 100 \% \\
& =0,7 \%
\end{aligned}
$$

Hasil pengujian secara keseluruhan terdapat pada Tabel 7. Dari tabel 7, dapat diperoleh informasi bahwa jumlah total paket yang hilang sangat kecil dan tidak dipengaruhi oleh lama waktu pengujian dan tidak juga dipengaruhi oleh variasi bandwidth. Karena hasil yang didapatkan memiliki nilai yang berubah-ubah pada setiap variasi bandwith yang diuji. Kemudian perbandingan packet loss pada pengujian selama 30 detik, 60 detik dan 90 detik, nilai packet loss yang lebih baik didapatkan pada pengujian selama 90 detik. Meskipun nilai packet loss yang didapatkan tidak menentu, namun hasil pengujian tersebut menunjukkan bahwa packet loss dari 
setiap settingan bandwith dengan pengujian selama 30 detik, 60 detik dan 90 detik bernilai sangat kecil dan mendekati 0 (nol). Sehingga dapat dikatakan pengukuran packet loss berada pada kategori yang sangat baik berdasarkan standar TIPHON, yang dimana $0 \%$ merupakan kategori yang sangat bagus. Seperti yang terdapat pada hasil pengujian Tabel 8:

Tabel 8 hasil pengujian packet loss.

\begin{tabular}{clllllllll}
\hline \multicolumn{7}{c}{ Hasil Pengujian Packet Loss } \\
\hline \multicolumn{7}{c}{30 sec } & \multicolumn{7}{c}{60 sec } \\
\hline Pengujian & 128 & 256 & 512 & 128 & 256 & 512 & 128 & 256 & 512 \\
& Kbps & Kbps & Kbps & Kbps & Kbps & Kbps & Kbps & Kbps & Kbps \\
P.1 & 0,7 & 0,3 & 0,6 & 0,3 & 0,2 & 0,8 & 0,4 & 0,1 & 0,2 \\
P.2 & 0,6 & 0,3 & 0,6 & 0,2 & 0,1 & 0,4 & 0,2 & 0,1 & 0,3 \\
P.3 & 0,6 & 0,4 & 1 & 0,4 & 0,1 & 0,2 & 0,1 & 0,1 & 0,2 \\
P.4 & 0,6 & 0,3 & 0,7 & 0,3 & 0,3 & 0,2 & 0,4 & 0,1 & 0,2 \\
P.5 & 0,6 & 0,3 & 0,7 & 0,6 & 0,2 & 0,1 & 0,3 & 0,1 & 0,2 \\
P.6 & 0,3 & 0,2 & 0,7 & 0,4 & 0,2 & 0,2 & 0,3 & 0,1 & 0,1 \\
P.7 & 0,4 & 0,1 & 0,8 & 0,7 & 0,1 & 0,2 & 0,4 & 0,1 & 0,1 \\
Rata-rata & $0,54 \%$ & $0,27 \%$ & $0,72 \%$ & $0,41 \%$ & $0,17 \%$ & $0,3 \%$ & $0,3 \%$ & $0,1 \%$ & $0,18 \%$ \\
\hline
\end{tabular}

Dari Tabel 8 diatas didapatkan informasi hasil pengujian terlihat bahwa kecepatan transfer data dari variasi bandwith yang diuji mengalami kondisi naik turun pada setiap settingan bandwidth dengan pengujian selama 30 detik, 60 detik dan 90 detik. Hal ini terlihat seperti capture wireshark pada Gambar 5.

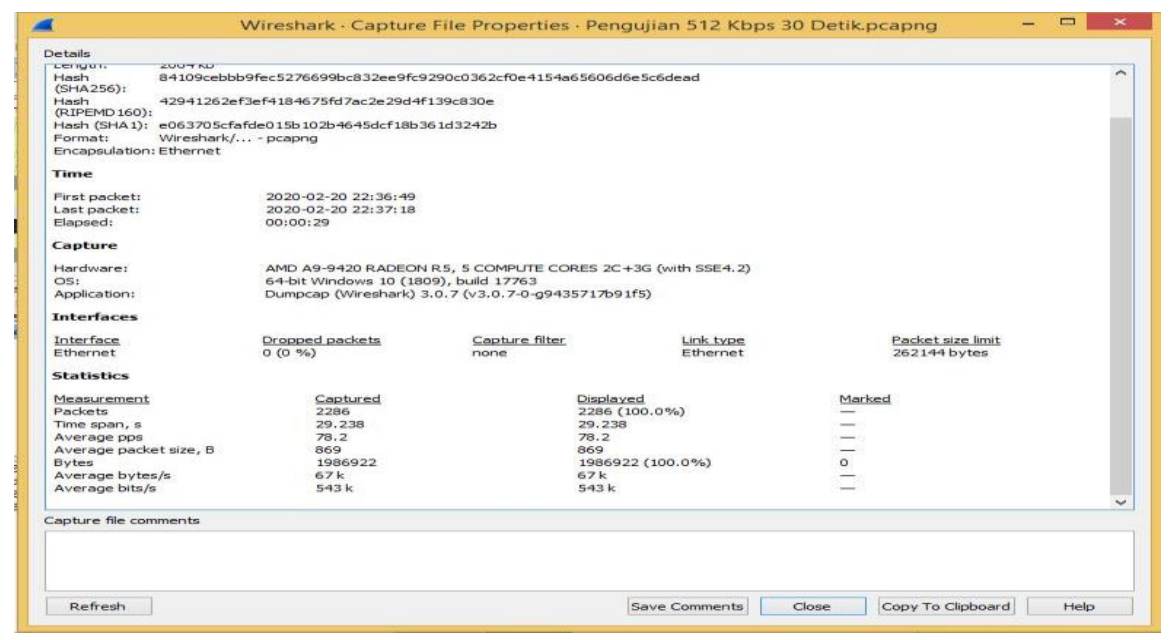

Gambat 5 Hasil capture parameter throughput

Kemudian perbandingan throughput pada pengujian selama 30 detik, 60 detik dan 90 detik, nilai throughput yang lebih baik didapatkan pada pengujian selama 30 detik. Namun meskipun demikian, nilai throughput dari variasi bandwidth $128 \mathrm{kbps}, 256 \mathrm{kbps}$, dan $512 \mathrm{kbps}$ menunjukkan nilai yang baik karena dari hasil transfer data tersebut diperoleh nilai lebih dari 100. Ini menunjukan throughput berada pada kategori yang sangat baik berdasarkan standar TIPHON, yang dimana 100 merupakan kategori yang sangat bagus. 
Tabel 9 Hasil pengujian throughput

\begin{tabular}{clllllllll}
\hline \multicolumn{8}{c}{ Hasil Pengujian Pada Parameter Throughput } \\
\hline \multicolumn{7}{c}{ 30sec } & \multicolumn{7}{c}{60 sec } \\
\hline Pengujian & 128 & 256 & 512 & 128 & 256 & 512 & 128 & 256 & 512 \\
& Kbps & Kbps & Kbps & kbps & Kbps & Kbps & kbps & Kbps & Kbps \\
P.1 & 149 & 283 & 543 & 147 & 281 & 323 & 146 & 211 & 320 \\
P.2 & 145 & 282 & 548 & 145 & 281 & 309 & 146 & 215 & 315 \\
P.3 & 146 & 280 & 537 & 146 & 280 & 463 & 146 & 213 & 208 \\
P.4 & 148 & 281 & 529 & 147 & 281 & 467 & 148 & 212 & 210 \\
P.5 & 147 & 280 & 536 & 147 & 281 & 465 & 146 & 216 & 212 \\
P.6 & 148 & 281 & 541 & 149 & 280 & 469 & 146 & 214 & 210 \\
P.7 & 148 & 281 & 537 & 148 & 281 & 464 & 147 & 215 & 310 \\
Rata-rata & 147 & 281 & 538 & 147 & 280 & 422 & 146 & 213 & 255 \\
& kbit/s & kbit/s & $\mathrm{kbit} / \mathrm{s}$ & $\mathrm{kbit} / \mathrm{s}$ & $\mathrm{kbit} / \mathrm{s}$ & $\mathrm{kbit} / \mathrm{s}$ & $\mathrm{kbit} / \mathrm{s}$ & $\mathrm{kbit} / \mathrm{s}$ & $\mathrm{kbit} / \mathrm{s}$ \\
\hline
\end{tabular}

Berdasarkan tabel 9 diatas pada posisi nilai rata-rata parameter througput sangat baik pada pengujian pada kecepatan 30sec, $60 \mathrm{sec}$ dan $90 \mathrm{sec}$ diperoleh masing-masing melebihi bandwidh $100 \mathrm{kbit} / \mathrm{s}$ yang menunjukkan kondisi yang stabil. Hal tersebut dinyatakan bahwa aplikasi Gnomp3d yang terpasang pada VPS sangat baik jika dijalankan pada konsisi banwidh yang rendah mapun yang tinggi.

\section{Kesimpulan}

Dari hasil penelitian yang telah dilakukan dan melakukan analisa terhadap Quality Of Service (QoS) yang telah di lakukan pada audio streaming yang dibangun menggunakan GNUMP3d sebagai server media streaming pada VPS dengan parameter QoS meliputi Delay, Jitter, Packet loss, dan Throughput maka dosimpulkan bahwa QoS audio streaming yang dihasilkan oleh penggunaaan Aplikasi Gnump3d berkualitas sangat bagus berdasarkan ketentuan standard TIPHON pada parameter delay,packet loss dan Througput, jika diuji coba dengan bentuk variasi bandwidth 128kbps, 256kbps, $512 \mathrm{kbps}$ dan delay 30sec, 60sec, 90sec diperoleh nilai parameter delay dengan rata-rata $44,94 \mathrm{~ms}<150 \mathrm{~ms}$, Packet Loss dengan rata-rata prosentase $0.33 \%<5 \%$ dan Througput 269kbit/s $>100$. Sedangkan QoS yang buruk dihasilkan oleh paramter Jitter Sebesar $11.675 \mathrm{~ms}$ yang melebihi dari range $125 \mathrm{~ms}-255 \mathrm{~ms}$ yang tetapkan TIPHON. Untuk memperoleh hasil penelitian yang lebih realibel maka diperlukan penelitian lanjutan dengan parameter yang sama dengan menggunakan jenis topologi jaringan WAN yang melibatkan lebih banyak perangkat jaringan dengan desain topologi yang berbeda sehingga penerapan aplikasi Gnump3d dapat lebih teruji QoS yang dihasilkan.

\section{Ucapan Terima Kasih}

Terima kasih peneliti ucapkan kepada pihak-pihak yang terlibat dalam penelitian ini, para mahasiswa yang ikut membantu menyiapkan software dan hardware yang diperlukan guna mendukung terselesainya penelitian ini, semoga penelitian ini dapat bermanfaat untuk para pembaca dan penelitian dapat digunakan sebagai rujukan dalam penelitian-penelitian sejenis.

\section{Referensi}

[1] A. Subandi, "Implementasi dan analisis QoS (Quality Of Service) pada VoIP (Voice Over Internet Protocol) Berbasis Linux," vol. 5, no. 2, 2018.

[2] G. Geovani, "On-Demand Audio Streaming Menggunakan Metode Peer to Peer Block 
Scheduling," Univ. Brawijaya, vol., no. 12-19, p. 2, 2013.

[3] H. Fahmi, "Analisis QoS (Quality Of Service) Pengukuran Delay,Jitter,Packet Loss dan Throughput Untuk Mendapatkan Kualitas Kerja Radio Streaming Yang Baik," Teknol. Inf. dan Komunuikasi, vol. 7, no. 2, pp. 98-105, 2018.

[4] A. W. Isnanta and M. T. Kurniawan, "Perancangan Jaringan Multiprotocol Label Switching Menggunakan metode NDLC Untuk Layanan VOIP DAN Streaming Video Universitas Telkom," Proceeding Eng., vol. 4, no. 2, pp. 3049-3056, 2017.

[5] Ahmad Jaelani, "Metode - Metode dalam Metodologi Peneitian," student.unsika.ac.id, 2014. .

[6] R. Kurniawan, "Analisis Dan Implementasi Desain Jaringan Hotspot Berbasis Mikrotik Menggunakan Metode NDLC (Network Development Life Cycle) Pada BPU Bagas Raya Lubuk Linggau," J. Ilm. Betrik, vol. 7, no. 01, pp. 50-59, 2016, doi: 10.36050/betrik.v7i01.12.

[7] D. Kurnia, "Analisis QoS pada Pembagian Bandwidth dengan Metode Layer 7 Protocol, PCQ, HTB dan Hotspot di SMK Swasta Al-Washliyah Pasar Senen," CESS (Journal Comput. Eng. Syst. Sci., vol. 2, no. 2, pp. 102-111, 2017, doi: 10.24114/cess.v2i2.6541.

[8] A. F. Cobantoro, "Analisa QoS (Quality Of Service) Pada Jaringan RT-RW Net Dengan Kendali Rasbery PI," Netw. Eng. Res. Oper., vol. 4, no. 1, pp. 0-6, 2018, doi: 10.21107/nero.v4i1.109.

[9] R. Wulandari, "Analisa QoS (Quality Of Service) Pada Jaringan Internet (Studi Kasus: UPT Loka Uji Teknik Penambangan Jampang Kulon-LIPI)," J. Tek. Inform. dan Sist. Inf., vol. 2, no. 2, pp. 162-172, 2016, doi: 10.28932/jutisi.v2i2.454.

[10] K. A. Farly, X. B. N. Najoan, and A. S. M. Lumenta, "Perancangan Dan Implementasi Vpn Server Dengan Menggunakan Protokol Sstp (Secure Socket Tunneling Protocol) Studi Kasus Kampus Universitas Sam Ratulangi," J. Tek. Inform., vol. 11, no. 1, 2017, doi: 10.35793/jti.11.1.2017.16745.

[11] F. A. Afrida and S. Rahmatia, "Analisis Internet Group Management Protocol (IGMP) Menggunakan Software Wireshark dalam Layanan Live Streaming IPTV pada Multi Service Access Network (MSAN) di Area Darmo, Surabaya," J. Al-AZHAR Indones. SERI SAINS DAN Teknol., vol. 4, no. 4, p. 176, 2018, doi: 10.36722/sst.v4i4.307. 